\title{
Atuação do assistente social em contingência de vazamento de substância química envolvendo comunidade
}

\author{
Emanuel Jones Xavier Freitas*
}

\begin{abstract}
Resumo
Entre outros profissionais, o assistente social é historicamente requisitado para o enfrentamento de situações contingenciais das mais diversas naturezas. Neste contexto, observa-se que as estratégias profissionais para intervenção se constroem e se reconstroem a partir das particularidades evidenciadas no processo de trabalho profissional, sendo relevante a sistematização das informações para elaboração de referenciais que possam nortear o trabalho profissional, à medida em que se fizer necessário. $\mathrm{O}$ presente relato de experiência apresenta uma síntese descritiva e reflexiva da ação profissional de assistentes sociais requeridos para atuar em contingência de vazamento de substância química envolvendo comunidade, ocorrida na Grande São Paulo (Brasil), em outubro de 2016.
\end{abstract}

Palavras-chave: assistente social; serviço social; contingência; emergência; comunidade.

\section{Performance of the Social Worker in the contingency of chemical substance leakage involving community}

\begin{abstract}
Among other professionals, the social workers is historically required to deal with contingency situations of the most diverse nature. In this context, it is observed that the professional strategies for intervention are constructed and reconstructed based on the particularities evidenced in the professional work process, being relevant the systematization of the information for the elaboration of references that can guide the professional work, as necessary. The present report of experience presents a descriptive and reflexive synthesis of the action professionals of social workers required to act in contingency of leak of chemical substance involving community, occurred in Greater São Paulo (Brazil), in October 2016.
\end{abstract}

Keywords: social worker; social work; contingency; emergency; community.

\footnotetext{
*Assistente Social (CRESS/SP 39524/9) pelo Centro Universitário Assunção (UNIFAI, 2008), especialista em Gestão de Projetos Sociais em Organizações do Terceiro Setor (PUC/SP, 2012), mestre em Administração pela Universidade Presbiteriana Mackenzie, (UPM, 2015), linha de pesquisa Gestão Humana e Social nas Organizações. Atualmente desenvolve atividades de Coordenação do Curso de graduação e de Estágios em Serviço Social na Universidade de Santo Amaro - UNISA, atuando ainda como docente no Centro Universitário Ítalo Brasileiro e como Assistente Social Organizacional na Petrobras Transportes - TRANSPETRO S.A. Possui ampla experiência em Serviço Social Organizacional com foco em Gestão de Saúde Corporativa e Qualidade de Vida no Trabalho e também em Assistência Médica Domiciliária, prestando serviços eventuais de elaboração de material didático instrucional em diversas instituições de ensino superior.
} 


\section{Introdução}

Situações de contingência ou emergência são historicamente relacionadas a uma dada situação de caos, insegurança ou ausência de uma regular disponibilidade dos recursos necessários para a manutenção das atividades de vida diária. Neste contexto, o assistente social é requerido como profissional que promoverá o restabelecimento das condições concretas de vida, ou do atendimento mínimo às necessidades de indivíduos ou grupos sociais.

No recorte realizado pelo presente relato de experiência, os assistentes sociais que figuram no cenário, são contratados de uma grande empresa de exploração e logística de combustíveis fósseis no Brasil, requeridos para intervir em situação de vazamento de substância química ${ }^{1}$, ocasionada por ação criminosa de roubo de combustível, em região urbana, amplamente habitada e localizada à região leste da cidade de São Paulo, divisa com o município de Guarulhos.

\section{Características socioterritoriais}

A região afetada pelo vazamento da substância química está localizada na região leste da cidade de São Paulo, entre as unidades territoriais de Itaquera e São Miguel Paulista. Dados oficiais (IBGE, 2010) apontam que em 2010, a população estimada da região configurava-se em 142.372 residentes fixos, estimando-se significativo aumento populacional até 2016, dado que entre 1980 e 2010 o aumento médio da população nesta unidade territorial foi de $70 \%$.

Em 2010, a região afetada discriminava-se pela existência de 41.705 residências (IBGE, 2010), cuja quantidade média de moradores por residência era de 3 a 5 pessoas (entre crianças e adultos). Trata-se de região vulnerável sob o ponto de vista da oferta pública de serviços, especialmente aqueles relacionados aos segmentos de assistência social, saúde, educação e lazer.

Trata-se de uma região cujas referências iniciais de existência datam da década de 1950 e que, na atualidade, destaca-se predominantemente pela existência de loteamentos originalmente clandestinos, atualmente desmembrados ou subdivididos, sob os quais constam instalados há média de 5 a 6 metros de profundidade, dutos metálicos para a transferência de diferentes substâncias químicas com fins à produção de combustíveis fósseis.

\section{Fenômeno objeto da ação dos assistentes sociais}


Aos 25 de outubro de 2016, um dos assistentes sociais contratados pela empresa logística administradora das instalações de distribuição de combustíveis, foi contatado pela equipe de Gerenciamento de Emergências da mesma organização, ocasião em que foi informado a respeito da ocorrência do vazamento de substância química por ação criminosa, bem como, que o território afetado tratava-se de uma região densamente habitada e que, a partir de avaliação realizada pela Defesa Civil do município, seria necessária a desmobilização de algumas famílias para abrigo previamente viabilizado pela empresa.

Neste contexto, demandou-se a intervenção do assistente social para atendimento $e$ acompanhamento social das famílias, dada a necessidade de desmobilização de seu ambiente residencial e a abrupta mudança em suas atividades diárias e rotinas previamente estabelecidas sem qualquer previsão de restabelecimento.

O atendimento social, conforme Freitas (2016:5-6):

(...) refere-se ao processo de trabalho próprio do assistente social, em que mediado pelo diálogo e a partir de um fenômeno ou intercorrência de natureza social, o profissional busca informações para aprofundamento e levantamento de dados relevantes para, por meio de seu arcabouço teórico-metodológico, ético-político e técnico-operativo, propor encaminhamentos e tratativas ao enfrentamento da situação apresentada.

Diante do exposto, o profissional assistente social prestou atendimento social, por meio de orientações técnicas e acompanhamento, à população afetada pelo vazamento de substância química, inicialmente no cenário do abrigo (hotel reservado pela empresa) e, num segundo momento, também in loco, na área afetada pela intercorrência social já mencionada.

A ação profissional estendeu-se entre o período de 25 a 29 de outubro de 2016, demandando ações residuais ao longo de todo o mês de novembro do mesmo ano.

\section{Perfil da população atendida}

Foram desmobilizadas das residências afetadas pelo vazamento de substância química 67 moradores, dos quais 39\% foram encaminhados ao abrigo providenciado pela empresa, em detrimento de $61 \%$ que optaram por permanecer abrigados nas residências de familiares e/ou colaterais residentes nas imediações do bairro de moradia.

Gráfico 1 - População total residente por faixa etária 




Fonte: Elaborado pelo autor

Sob a análise da população total residente por faixa etária ${ }^{2}$, observa-se predominância da população adulta (entre 19 e 59 anos) em 53\%, seguida de crianças e adolescentes em 18\% e de idosos, em $17 \%$.

A ocorrência de vínculos formais ou informais de trabalho, bem como, vínculos escolares em diferentes níveis (educação básica ou superior) estavam adequados aos pressupostos legais em relação ao perfil dos usuários atendidos. Observou-se, ainda na ocasião, de forma isolada, intercorrências de cunho psiquiátrico manifestado através do uso indevido de substâncias psicoativas (drogadição).

\section{Ação profisssional do assistente social}

Dadas as características principais sob o ponto de vista socioterritorial e sociodemográfico, a ação profissional dos dois assistentes sociais envolvidos na intervenção buscou por meio de uma ação integrada e transdisciplinar oferecer subsídios para o enfrentamento da situação de risco a qual foram expostos os moradores do território afetado.

Conforme reflete Santos (2011:36):

Atualmente, pode-se considerar que os desastres socioambientais constituem-se como ameaças à vida social, especialmente às populações que vivenciam a exclusão socioespacial e a socioeconômica, que são, majoritariamente, as mais afetadas nesses contextos.

Neste sentido, a ação profissional dos assistentes sociais envolvidos desenvolveu-se na perspectiva de:

1. Prestação de atendimento social e gestão do abrigo:

a. Um dos assistentes sociais envolvidos na ação esteve presente a todo momento, desde o acolhimento dos moradores desmobilizados até sua saída do 
abrigo, com a finalidade de prestar esclarecimentos a respeito do processo de saneamento do vazamento de substância química no bairro de moradia dos usuários envolvidos, além de oferecer atendimento e orientação social em relação a demandas específicas dos usuários, organizando e viabilizando condições logísticas para comparecimento a trabalho, escola e/ou serviços de saúde, garantindo-lhes os acessos necessários às atividades de vida diária.

2. Prestação de atendimento social e intermediação de conflitos in loco;

a. Realização de atendimento social e intermediação de conflitos junto à comunidade no local da ocorrência, oferecendo orientações a respeito dos moradores desmobilizados a familiares e colaterais ainda presentes no local da ocorrência, bem como, promovendo a intermediação de conflitos na relação entre equipe técnica e cidadãos envolvidos no processo de saneamento do vazamento, além de subsidiar empresa e comunidade a respeito de informações sociais relevantes.

Um ponto importante a se destacar no processo de prestação do atendimento social, versa a respeito das condições éticas e técnicas de atuação profissional, prescritas na resolução CFESS n. ${ }^{\circ}$ 493/2006, que precisam ser objeto de atenção frequente dos assistentes sociais no exercício de sua função, com o objetivo principal de resguardo ao princípio ético do sigilo profissional.

A mencionada resolução, em seu artigo $2^{\circ}$, orienta que:

Art. $2^{\circ}$ - O local de atendimento destinado ao assistente social deve ser dotado de espaço suficiente, para abordagens individuais ou coletivas, conforme as características dos serviços prestados, e deve possuir e garantir as seguintes características físicas:

a. iluminação adequada ao trabalho diurno e noturno, conforme a organização institucional;

b. recursos que garantam a privacidade do usuário naquilo que for revelado durante o processo de intervenção profissional;

c. ventilação adequada a atendimentos breves ou demorados e com portas fechadas;

d. espaço adequado para colocação de arquivos para a adequada guarda de material técnico de caráter reservado. (CFESS, 2011:153 - grifo nosso)

A este respeito, deve-se ponderar que por tratar-se de uma situação contingencial, o cenário da intercorrência ou mesmo do abrigo, não necessariamente estariam estruturados na perspectiva defendida pela mencionada resolução. No entanto, como parte dos desafios a serem cotidianamente enfrentados pelos assistentes sociais, está a necessidade da construção 
de estratégias que defendam e arquitetem possibilidades para um trabalho profissional respeitado e qualificado.

Infelizmente a indisponibilidade de uma estrutura material adequada aos pressupostos da ação profissional não parece ser uma particularidade de situações contingenciais em que o assistente social é requisitado.

\begin{abstract}
Ressalta-se que o espaço físico constitui um dos elementos necessários para garantir o acolhimento ao usuário, bem como a qualidade do trabalho prestado pelo assistente social. Contudo, pesquisas sobre as tendências do mercado de trabalho do Serviço Social revelam que essa não tem sido a realidade vivenciada por muitos profissionais no Brasil. Os problemas elencados pelos assistentes sociais abarcam dificuldades financeiras, ausência de material de expediente e de móveis de escritório compatíveis com a necessidade dos profissionais. (FAERMANN; MELLO, 2016 p:104)
\end{abstract}

Diante de tal situação, entende-se caber ao profissional avaliar o contexto, ponderando a importância de assumir uma conduta não fatalista ou messiânica (IAMAMOTO, 2001), ou ainda mesmo de um militantismo estéril (BARROCO, 2003), mas uma conduta estrategicamente elaborada. Crê-se que para o exercício profissional competente e alinhado às prescrições legais das entidades representativas da categoria, os assistentes sociais devem avaliar o cenário e construir possibilidades viáveis concretamente.

Nesta direção e no contexto da intervenção apresentada neste relato, os atendimentos sociais eram realizados nos quartos em que os grupos familiares estivessem abrigados, bem como, as reuniões eram realizadas em espaço coletivo, reservado ao público de interesse em questão.

Sobre o aspecto da ação profissional faz-se relevante destacar a dimensão técnicooperativa que viabilizou o exercício profissional, considerando sua importância no processo de consolidação da aplicação técnica do trabalho profissional.

Toso (apud LIMA; MIOTO 2009:27) afirma a partir da ótica instrumental do atendimento direto aos usuários:

(...) que a complexidade das ações dos Assistentes Sociais reside em um conjunto de fatores que as tornam altamente variáveis, imprevisíveis e sujeitas a contínuas transformações. Dentre esses fatores estariam: os tipos de demandas que requerem modalidades operativas flexíveis e personalizadas; a quantidade e a multidimensionalidade dos problemas sociais dos quais sempre emergem novas demandas e necessidades; a multiplicidade de contextos institucionais em interação com os seus constantes conflitos de competências e coordenação; a incerteza em relação aos recursos devido à grande variação da disponibilidade dos recursos públicos; e a complexidade das respostas somada à incerteza sobre seus efeitos, dado o grande número de variáveis intervenientes e da dificuldade em controlá-las.

Considerando, portanto, a complexidade inerente ao exercício profissional e a necessidade da elaboração customizada de um arsenal técnico-operativo específico para a 
ação profissional, fez-se necessário aos profissionais intervenientes e elaboração de um conjunto de instrumentos com a finalidade de operacionalizar a técnica-profissional, dada a diversidade de intercorrências que emergiam no contexto do processo de acompanhamento social dos usuários envolvidos.

$\mathrm{Na}$ perspectiva das tipologias das intercorrências sociais apresentadas, destacaram-se as seguintes atividades pelos assistentes sociais envolvidos na contingência:

1. Realização de reuniões de orientação a respeito das obras de saneamento;

a. Foram realizadas cotidianamente ao longo de todo o período de prestação de atendimento aos usuários em questão, reuniões para repasse de informações relevantes a respeito do trabalho de saneamento do vazamento de substância química, bem como, informações que fossem relevantes aos usuários de forma geral. As reuniões eram sistematicamente registradas em ata, com a finalidade de garantir ciência e compreensão a respeito dos temais discutidos.

2. Providência de roteiros logísticos para cumprimento das atividades de vida diária;

a. Além da fixação de uma linha de transportes diária entre abrigo e comunidade, eram providenciados roteiros logísticos pré-fixados e personalizados de forma a garantir aos usuários envolvidos, que estes, seguissem atendendo a seus compromissos, tais como vínculos de trabalho, escola ou mesmo atendimento em serviços de saúde.

3. Intermediação entre abrigados para garantia de ambiência;

a. O assistente social responsável pelo acompanhamento dos usuários abrigados, frequentemente intervia promovendo intermediação com a finalidade de interceder em situações de conflito emergentes na relação entre os usuários abrigados.

4. Emissão de declarações de ausência;

a. Para o caso de assimetrias logísticas ou situações em que o atendimento à compromissos adquiridos pelos usuários não eram cumpridos, era fornecida pelos assistentes sociais envolvidos, uma declaração de ausência. Neste instrumento, assinado e preenchido estritamente pelo assistente social, eram fornecidas as informações necessárias para que o interlocutor adquirisse a informação a respeito da contingência em questão e da eventual impossibilidade do usuário em comparecer ao compromisso (escola, trabalho, tratamentos, etc.), além de eventual contato telefônico para esclarecimentos. 


\section{Contatos colaterais;}

a. Foram realizados frequentes contatos com as partes interessadas no processo de atendimento aos usuários envolvidos, especialmente aqueles relacionados ao acompanhamento das obras de saneamento para repasse de informações aos moradores envolvidos, bem como junto a empregadores, familiares, imprensa, etc.

6. Direcionamento de reclamações ao setor de ouvidoria da empresa;

a. Manifestações de descontentamento ou mesmo de situações de perda financeira (especialmente entre moradores que desenvolviam atividades profissionais em suas residências, entre outras questões) eram direcionadas diretamente ao serviço de ouvidoria da empresa, com a finalidade de oferecer respostas qualificadas e objetivas às necessidades da população envolvida.

Para a consecução das atividades em questão, foram organizados sob o ponto de vista técnico-operativo os seguintes instrumentais:

1. Declaração para justificativa de ausência;

a. Instrumento emitido para empregadores, escolas e serviços de saúde para justificativa de ausência, caso solicitado pelo usuário.

2. Ficha de atendimento;

a. Instrumento para coleta de informações relevantes ao atendimento e acompanhamento social, além da utilização para obtenção e sistematização de informações socioterritorias e sociodemográficas dos usuários. Utilizando-o igualmente para evolução do acompanhamento social e composição do prontuário dos grupos familiares atendidos.

O trabalho profissional dos assistentes sociais envolvidos foi desenvolvido numa perspectiva multidisciplinar, à medida em que embora todos os profissionais envolvidos estivessem empreendendo esforços para o saneamento da situação já mencionada, os assistentes sociais mantiveram centralidade na atenção e atendimento às necessidades sociais oriundas do processo de desmobilização dos moradores da região afetada pelo vazamento de substância química, sem que sua autonomia ou competências profissionais fossem maculadas ou questionadas no contexto da contingência e na sua relação com demais trabalhadores envolvidos, comunidade, gestores ou órgãos públicos envolvidos. 
Finalmente, após o processo de saneamento do vazamento de substância química e realização de vistoria pela Defesa Civil, as residências foram liberadas e os moradores, tanto aqueles abrigados em local providenciado pela empresa, quanto aqueles abrigados junto à familiares e/ou colaterais, foram redirecionados às suas casas, ainda sob orientação e acompanhados dos assistentes sociais envolvidos.

Por óbvio, ações de outras naturezas foram empreendidas para atendimento a esta contingência, tais como a) hospedagem de animais, b) segurança patrimonial das residências cujas famílias foram desmobilizadas, c) assessoria de imprensa para repasse de informações diversas à mídia, b) plantões médicos, entre outras. No entanto, o fato de o presente trabalho versar a respeito de um relato de experiência nos limita a abordar a situação dando centralidade a ação dos assistentes sociais envolvidos no processo.

\section{Considerações finais}

Ao final da intercorrência, observou-se que muito embora a situação per si tenha exposto os moradores afetados pelo vazamento a um elevado nível de estresse, especialmente pela necessidade de desmobilização, a intervenção dos assistentes sociais foi importante para o atendimento às necessidades de natureza social apresentadas pelos usuários envolvidos, seja na mobilização de recursos humanos e/ou materiais para a dissolução de problemas, seja na arrefecimento dos conflitos emergentes em situações contingenciais.

Nesta perspectiva, o posicionamento e os compromissos políticos da categoria profissional dos assistentes sociais em relação a determinados valores e princípios, assentados em referências teóricas, no contexto da contingência em questão, expressaram-se numa concepção de homem e de sociedade, traduzindo-se nas ações profissionais empreendidas, atendendo às prescrições teóricas a respeito do desafio atual da profissão quanto a efetivação de seu projeto profissional (IAMAMOTO, 2002), condição esta que apenas se enrijece por meio da articulação das dimensões ético-políticas, teórico-metodológicas, técnico-operativas, acadêmicas e legais.

Percebeu-se na relação com trabalhadores e comunidade no período pós-contingência que a ação dos profissionais assistentes sociais contribuiu fortemente para a qualidade da intervenção de saneamento do vazamento envolvendo substância química e comunidade, sendo bem avaliada e qualificada verbalmente no discurso dos sujeitos envolvidos.

Observou-se, no entanto, sob o ponto de vista teórico, a ausência de referenciais que norteassem a ação profissional em situações de contingência, aspecto que sob nossa ótica 
merece atenção e dedicação dos profissionais assistentes sociais que devem ser convidados a sistematizar sua ação profissional, constituindo elementos que possibilitem a criação de direcionamentos e referências para a elaboração de planos de ação profissionais.

\section{Referências bibliográficas}

BARROCO, M. L. Ética e Serviço Social. 2.ed. São Paulo: Cortez, 2003.

EBC Agência Brasil - Interdição de casas por vazamento de nafta em São Paulo já dura mais de 48 horas. Disponível em: <http://agenciabrasil.ebc.com.br/geral/noticia/201610/interdicao-de-casas-por-vazamento-de-nafta-em-sao-paulo-ja-dura-mais-de-48>. Acesso em 7 de abril de 2017.

FAERMANN, L. A.; MELLO, C. C. V. As condições de trabalho dos assistentes sociais e suas implicações no processo de adoecimento dos profissionais. Textos \& Contextos (Porto Alegre), v. 15, n. 1, p. 96 - 113, jan./jul. 2016.

FREITAS, E. J. X. Prescrição social: uma estratégia instrumental necessária para o atendimento às orientações profissionais. UNIÍTALO em Pesquisa, URL: www.italo.com.br/pesquisa. São Paulo SP, v.6, n.3, p. 165-180, jul/2016. Disponível em < http://pesquisa.italo.com.br/>. Acesso em: 05 de abril de 2017.

IAMAMOTO, M. V. O Serviço Social na Contemporaneidade: trabalho e formação profissional. 5.ed. São Paulo: Cortez, 2001.

. Projeto profissional, espaços ocupacionais e trabalho do assistente social na atualidade. In: CFESS-Conselho Federal de Serviço Social. As atribuições privativas do (a) assistente social em questão. Brasília: CFESS, fev. 2002, p. 13-50. Disponível em < http://www.cfess.org.b>. Acesso em: 06 de abril de 2017.

INSTITUTO BRASILEIRO DE GEOGRAFIA E ESTATÍSTICA (IBGE). Censo Brasileiro de 2010. Rio de Janeiro: IBGE, 2012.

LIMA, T. C. S; MIOTO, R. C. T. A dimensão técnico-operativa do Serviço Social em foco: sistematização de um processo investigativo. Revista Textos \& Contextos Porto Alegre v.8 n.1 p.22-48. jan./jun. 2009. Disponível em < http://www. revistaseletronicas.pucrs.br>. Acesso em: 06 de abril de 2017.

PREFEITURA MUNICIPAL DE SÃO PAULO, SECRETARIA DE PLANEJAMENTO. Infocidade (http://infocidade.prefeitura.sp.gov.br). Acesso em abril de 2017.

SANTOS, R. Gestão de desastres e política de assistência social. R. Katálysis, Florianópolis, v. 15, n. 1, p. 32-40, jan./jun. 2012. Disponível em < http://www.scielo.br >. Acesso em: 06 de abril de 2017.

\section{NOTAS}

\footnotetext{
${ }^{1}$ Informações sobre a intercorrência podem ser localizadas em diferentes canais de comunicação, entre eles http://agenciabrasil.ebc.com.br/geral/noticia/2016-10/interdicao-de-casas-por-vazamento-de-nafta-em-sao-pauloja-dura-mais-de-48

${ }^{2}$ Em razão falta de consenso entre os especialistas em relação aos critérios de agrupamento etário optou-se por agrupar crianças (até 12 anos incompletos) e adolescentes (12 a 18 anos de idade) conforme preconiza o Estatuto
} 
da Criança e do Adolescente (Lei ${ }^{\circ} 8.069$ de 13 de julho de 1990) e, idosos (60 anos ou mais de idade) o Estatuto do Idoso (Lei ${ }^{\circ} 10.741$ de 01 de outubro de 2003), contudo, agrupou-se na categoria adulto o número de habitantes com idade entre 19 a 59 anos de idade. 